\title{
Distribuição de raízes de laranja "Pêra" sob sequeiro e irrigação por microaspersão em solo arenoso(1)
}

\author{
Eugênio Ferreira Coelho(2), Francisco das Chagas Oliveira( ${ }^{(3)}$, \\ Eugênio Celso Emérito Araújo ${ }^{(4)}$ e Lúcio Flavo Lopes Vasconcelos ${ }^{(4)}$
}

\begin{abstract}
Resumo - O trabalho teve por objetivo avaliar a distribuição de raízes de laranja "Pêra" sob condições não-irrigadas e irrigadas por microaspersão em solo arenoso de tabuleiro costeiro. As raízes foram extraídas em trincheiras, a partir do tronco, nas direções longitudinal e ortogonal à fileira de plantas, pelo método do monolito. Uma vez separadas, foram digitalizadas com uso de computador e scanner, para obter, com o uso do software Rootedge, os comprimentos e diâmetros dos segmentos de raízes de todas as amostras, que foram mapeados nos perfis amostrados. O sistema radicular sob irrigação por microaspersão apresentou maior expansão, tanto em profundidade como em distância radial do tronco, do que o sistema radicular sob condições não-irrigadas. Houve maior porcentagem de raízes finas nos perfis de solo sob microaspersão, em relação à condição não-irrigada, indicando a possibilidade de maior atividade do sistema radicular nesse sistema de irrigação. As posições mais adequadas para instalação de sensores de água do solo para a cultura da laranja sob microaspersão estão entre 0 e 2,5 m de distância radial a partir do tronco, em profundidades entre 0 e $1,0 \mathrm{~m}$.
\end{abstract}

Termos para indexação: Citrus sinensis, sistema radicular, comprimento, densidade, enraizamento.

\section{Root distribution of "Pêra" orange trees under non-irrigated and irrigated conditions in a sandy soil}

\begin{abstract}
The objective of this work was to evaluate root distribution of orange cv. Pêra under non-irrigated and under microsprinkler irrigated conditions in a Coastal Plain Sandy Soil. Root samples were collected by monolith method from trenches, which were dug aside, the plant trunk at longitudinal and orthogonal directions to plant rows. After separation from soil, roots were scanned and digitized in a PC computer. Root length and diameter were determined using Rootedge software that allowed mapping root distribution on sampled soil profiles. Results showed that root system of microsprinkler irrigated trees occupied higher volume in the soil compared to the one under non-irrigated conditions. Higher amounts of fine roots were found in the profiles of microsprinkler irrigated trees that indicated higher root activity in those profiles compared to the non-irrigated ones. Results also showed that the most suitable locations for soil water sensor placement in orange orchards using microsprinkler irrigation are between 0 and $2.5 \mathrm{~m}$ of radial distance from the trunk, at depths between 0 and $1.0 \mathrm{~m}$.
\end{abstract}

Index terms: Citrus sinensis, root systems, length, density, rooting.

(1) Aceito para publicação em 15 de maio de 2001 Parcialmente financiado pelo Fundeci/Etene/Banco do Nordeste

(2) Embrapa-Centro Nacional de Pesquisa de Mandioca e Fruticultura, Caixa Postal 07, CEP 44380-000 Cruz das Almas, BA. Bolsista CNPq. E-mail: ecoelho@cnpmf.embrapa.br

(3) Universidade Federal da Bahia, Escola de Agronomia, CEP 44380-000 Cruz das Almas, BA. Bolsista da Capes.

(4) Embrapa-Centro de Pesquisa Agropecuária do Meio-Norte, Caixa Postal 01, CEP 64000-000 Teresina, PI E-mail: emerito@cpamn.embrapa.br

\section{Introdução}

A irrigação vem sendo reconhecida cada vez mais como uma tecnologia necessária aos pomares cítricos de várias regiões do Brasil, pela necessidade de aumento de produtividade e de qualidade dos frutos, no contexto de uma economia globalizada. $\mathrm{O}$ conhecimento da distribuição estática ou dinâmica do sistema radicular de qualquer cultura constitui uma relevante ferramenta para determinar a quantidade de água a ser aplicada no manejo da irrigação de uma cultura. Tratando-se de irrigação localizada, ou 
microirrigação, tal como a microaspersão, apenas o conhecimento da profundidade efetiva do sistema radicular não é suficiente para inferir as zonas de absorção de água e nutrientes, uma vez que a geometria de distribuição de água é de caráter multidimensional, e difere do caráter unidimensional da irrigação por aspersão. O conhecimento da distribuição do sistema radicular é também necessário para o posicionamento adequado dos sensores para monitoramento da água do solo no manejo da irrigação.

Além da necessidade do conhecimento da distribuição do sistema radicular para fins de irrigação, deve-se ressaltar a necessidade do mesmo para fins de manejo de solos. O manejo de solo pelo produtor repercute diretamente na distribuição das raízes, permitindo maior ou menor exploração do solo (Carvalho et al., 1999), e, conseqüentemente, na absorção de água e nutrientes pelas plantas.

Resultados de estudos sobre o sistema radicular de culturas cítricas (Zhang et al., 1996; Oliveira et al., 1998; Carvalho et al., 1999) têm sido fundamentais na avaliação do comportamento dos sistemas radiculares dessas culturas, e têm gerado benefícios no conhecimento do manejo e conservação do solo e água em diferentes condições edafoclimáticas.

O domínio e a distribuição do sistema radicular das culturas cítricas, da mesma forma que de outras culturas, depende das características físicas do solo, em especial da textura e estrutura, dos fatores genéticos, do teor de água do solo, que atua na resistência do solo à penetração das raízes, e é um dos componentes da distribuição de água/ar e da temperatura do solo (Gregory, 1987; Klepper, 1987).

A maioria dos estudos do sistema radicular dos citros (Oliveira et al., 1998; Carvalho et al., 1999) são realizados para as condições de sequeiro, quando não são direcionados para irrigação por aspersão. Dessa forma, a maior preocupação concentra-se no desenvolvimento das raízes em profundidade. No caso da irrigação por microaspersão, que gera um volume de solo úmido limitado, o pesquisador deve ater-se ao desenvolvimento radial das raízes em relação ao tronco, uma vez que este desenvolvimento estará condicionado ao movimento lateral da água no volume molhado.
Em condições de sequeiro, as raízes de plantas cítricas tendem a se concentrar nas camadas iniciais, isto é, entre 0 e $0,3 \mathrm{~m}$. Este fato foi comprovado por Zhang et al. (1996) e Carvalho et al. (1999) que encontraram $52 \%$ e $75 \%$ do total de raízes amostradas no perfil de solo entre 0 e $0,3 \mathrm{~m}$. Em condições de irrigação por gotejamento e microaspersão, Kanber et al. (1996) verificaram que $80 \%$ das raízes se encontraram na camada de 0 a $0,6 \mathrm{~m}$. Na irrigação por microaspersão, as informações sobre distribuição do sistema radicular dos citros têm sido escassas. Espera-se que os padrões de distribuição das raízes sejam influenciados pela distribuição multidimensional e desuniforme dos teores de água dentro do volume molhado do solo.

Este trabalho teve como objetivo avaliar os padrões de distribuição do sistema radicular da laranja Pêra, sob condição não-irrigada e irrigada por microaspersão, em solo arenoso de tabuleiro costeiro.

\section{Material e Métodos}

O trabalho foi desenvolvido na Embrapa-Centro de Pesquisa Agropecuária do Meio-Norte, no período entre 1997 e 1998, sendo a parte de campo executada na Unidade de Execução de Pesquisa de Parnaíba, PI, e a parte de processamento das raízes, em Teresina. O clima da região é equatorial marítimo, com temperatura média de $27^{\circ} \mathrm{C}$, umidade relativa média do ar de $75 \%$, e precipitação total anual entre 1.000 e $1.600 \mathrm{~mm}$, no período de janeiro-junho (Boletim Agrometeorológico, 1992). O solo da área é classificado como Latossolo Vermelho-Amarelo de textura arenosa, e pertence aos Tabuleiros Costeiros (Formação Barreiras do Terciário), classificado como areia franca, cujas características físico-hídricas médias no perfil de 0 a $1,0 \mathrm{~m}$ são: $481 \mathrm{~g} \mathrm{~kg}^{-1}$ de areia grossa, $384 \mathrm{~g} \mathrm{~kg}^{-1}$ de areia fina, $31 \mathrm{~g} \mathrm{~kg}^{-1}$ de silte, $104 \mathrm{~g} \mathrm{~kg}^{-1}$ de argila, densidade de $1,71 \mathrm{~kg} \mathrm{dm}^{-3}$ e porosidade total de $0,35 \mathrm{~m}^{3} \mathrm{~m}^{-3}$.

Foram selecionadas duas plantas de um pomar com idade de nove anos, a saber: uma, tomada de uma parte do pomar, correspondente a $33 \%$ do mesmo, irrigada por microaspersão desde o plantio, com um microaspersor por planta de vazão $70 \mathrm{~L} \mathrm{~h}^{-1}$, e uma, tomada de uma parte do pomar não-irrigada, também correspondente a $33 \%$ do mesmo. O espaçamento entre plantas foi de $7 \mathrm{~m} \times 5 \mathrm{~m}$. As plantas sob microaspersão apresentaram, na ocasião, diâmetro médio de copa de 4,3 m e altura média de planta de $3,7 \mathrm{~m}$, contra um diâmetro médio de copa de $2,6 \mathrm{~m}$ e uma altura média de planta não-irrigada de $2,6 \mathrm{~m}$. 
As amostras foram coletadas em trincheiras com direções ortogonais entre si, tendo a planta no centro. As trincheiras foram abertas junto à planta, na direção da fileira e na direção ortogonal à direção da fileira de plantas, perfazendo um total de quatro trincheiras por planta. Amostras correspondentes a blocos de solo de $0,15 \mathrm{~m} \mathrm{x}$ $0,15 \mathrm{~m} \times 0,15 \mathrm{~m}$ foram retiradas pelo método do monolito (Bohm, 1979) a partir do tronco até o semi-espaço entre plantas, quer na fileira de plantas, quer entre fileiras de plantas.

As amostras de solo e raízes foram levadas ao laboratório, para separação das raízes do solo por lavagem com água. A seguir, as raízes de determinada posição no perfil do solo foram classificadas conforme os diâmetros dos segmentos e colocadas em folhas de transparências, que foram levadas a um scanner de resolução de $600 \mathrm{dpi}$, escala $100 \%$ e intensidade de 100 a $130 \%$ para raízes mais grossas e $43 \%$ a $62 \%$ para raízes mais finas (Kaspar \& Ewing, 1997; Coelho et al., 1999). As imagens das raízes foram digitalizadas em arquivos TIFF (Tagged Image File Format).

Os arquivos TIFF foram, em seguida, descompactados e submetidos ao software Rootedge (Kaspar \& Ewing, 1997), para determinação das características geométricas: área, comprimento e diâmetro das raízes. Tendo em vista o número de arquivos ou o número de imagens geradas correspondentes a cada posição do perfil, os arquivos de saída do software Rootedge para cada posição tiveram vários valores de área, comprimento e diâmetro das raízes, conforme o número de arquivos gerados. Foi codificado um programa em Quick Basic, para obter, a partir desses arquivos referentes a determinada posição no perfil, a soma total dos comprimentos das raízes para aquela posição do perfil e separar os valores de diâmetros em cinco diferentes classes, conforme Bohm (1979): muito fina: $<0,5 \mathrm{~mm}$; fina: 0,5-2,0 mm; pouco fina: 2,0-5,0 mm; média: 5,0-10,0 mm; grossa: 10,0-20,0 mm; muito grossa: $>20,0 \mathrm{~mm}$.

Para cada bloco de solo de $3.375 \mathrm{~cm}^{3}$, referente a uma posição no perfil, foi determinada a densidade de comprimento de raízes (DCR) daquela amostra pela equação:

$\mathrm{DCR}=\mathrm{L}_{\mathrm{R}} / \mathrm{V}_{\mathrm{a}}$,

sendo a DCR dada em $\mathrm{cm} \mathrm{cm}^{-3}, \mathrm{~L}_{\mathrm{R}}$ o comprimento total de raízes da amostra em $\mathrm{cm}$, e $\mathrm{V}_{\mathrm{a}} \mathrm{o}$ volume da amostra, ou $3.375 \mathrm{~cm}^{3}$. Para fazer um mapeamento com objetivo de definir as regiões do sistema radicular de raízes mais finas ou mais grossas, para cada amostra, ou posição do perfil, determinou-se o comprimento total de raízes de cada classe de diâmetro (Bohm, 1979). O comprimento total das raízes de uma dada classe de diâmetro numa dada posição do perfil dividido pelo comprimento total de todas as raízes encontradas no perfil, independentemente do diâmetro, resultou na porcentagem das raízes de uma dada classe de diâmetro naquela posição.

\section{Resultados e Discussão}

Os valores absolutos das densidades de comprimento de raízes (DCR), bem como a distribuição dos mesmos nos perfis avaliados estiveram dentro das faixas de valores apresentados por Bowen (1985) para raízes de árvores (coníferas) em todos os perfis amostrados.

Tanto no perfil longitudinal como no perfil ortogonal à fileira de plantas, houve presença de raízes até 3,0 $\mathrm{m}$ de distância horizontal do tronco e nas profundidades de 0 a 2,0 $\mathrm{m}$ no perfil (Figura 1). As maiores concentrações de raízes (DCR) foram verificadas a diversas distâncias horizontais do tronco, de modo geral entre 0 e 1,0 $\mathrm{m}$ de profundidade. No caso do perfil ortogonal à fileira de plantas, altos valores de DCR ocorreram, também, na profundidade de 1,5 $\mathrm{m}$ abaixo do tronco.

Em geral, a distribuição de raízes no perfil tanto longitudinal como ortogonal à fileira de plantas foi limitada pela distância horizontal do tronco de $2,0 \mathrm{~m}$ e pela profundidade de $1,5 \mathrm{~m}$, valores inferiores aos registrados para a distribuição das raízes sob microaspersão (Figura 2). Nos dois perfis avaliados, a DCR foi superior a $0,05 \mathrm{~cm} \mathrm{~cm}^{-3}$ apenas na direção do eixo do tronco, à profundidade de $0,5 \mathrm{~m}$, indicando, assim, baixa densidade de raízes em todo o volume de solo explorado. Os máximos valores de DCR foram observados na profundidade $0,5 \mathrm{~m}$, abaixo do colo da planta.

As distribuições de raízes referentes aos dois perfis indicam que o sistema radicular sob microaspersão ocupou maior volume de solo, com maior profundidade e expansão lateral das raízes, de forma mais densa, isto é, com maiores valores de DCR em relação à condição não-irrigada.

No perfil ortogonal à fileira de plantas, as raízes finas e pouco finas (diâmetros entre 0,5 e 5,0 mm) foram encontradas em quase todo o perfil, com diversos pontos de concentração (Figura 3). As raízes de diâmetro acima de $5 \mathrm{~mm}$ ocorreram a distâncias horizontais do tronco inferiores a $2 \mathrm{~m}$, para profundidades de 0 a 1,5 m, e esta distância tendeu a diminuir com o aumento do diâmetro. 
No perfil longitudinal à fileira de plantas, o comportamento das raízes finas e pouco finas (diâmetros entre 0,5 e $5,0 \mathrm{~mm}$ ) foi o mesmo observado no perfil ortogonal, com maior incidência até a profundidade de 1,0 m. As raízes de diâmetros acima de 5,0 mm ocorreram a distâncias inferiores a $2 \mathrm{~m}$ e a profundidades também inferiores a $1,0 \mathrm{~m}$.

Tanto no perfil ortogonal, como no longitudinal, a profundidade de $0,5 \mathrm{~m}$ coincidiu com a região do perfil onde ocorreu maior incidência de todos os diâmetros de raízes (Figura 4). As raízes de diâmetro entre 0,5 e $2 \mathrm{~mm}$ ocorreram até $2 \mathrm{~m}$ do tronco, com maior incidência entre 0,5 e $2 \mathrm{~m}$ de distância do tronco, à profundidade de $1,0 \mathrm{~m}$ no perfil ortogonal à fileira de plantas e com maior incidência a $0,2 \mathrm{~m}$, e a 1,0 m de distância do tronco, à profundidade de $0,5 \mathrm{~m}$ no perfil longitudinal à fileira de plantas. Diâmetros superiores a $2 \mathrm{~mm}$ ocorreram até $2 \mathrm{~m}$ do tronco em ambos os perfis amostrados, mas as maiores incidências de raízes desses diâmetros estiveram a distâncias inferiores a 1,3 $\mathrm{m}$ do tronco. No caso de diâmetro de raízes superiores a $5 \mathrm{~mm}$, exceto para as de diâmetros entre 5 e $10 \mathrm{~mm}$ no perfil ortogonal à fileira de plantas, as demais ocorreram em maior incidência até a profundidade de 1,0 m para ambos os perfis.

A distribuição de raízes pelo sistema de microaspersão mostrou maior uniformidade em torno da planta, o que flexibiliza a aplicação de fertilizantes e a instalação de sensores de água do solo. Quanto

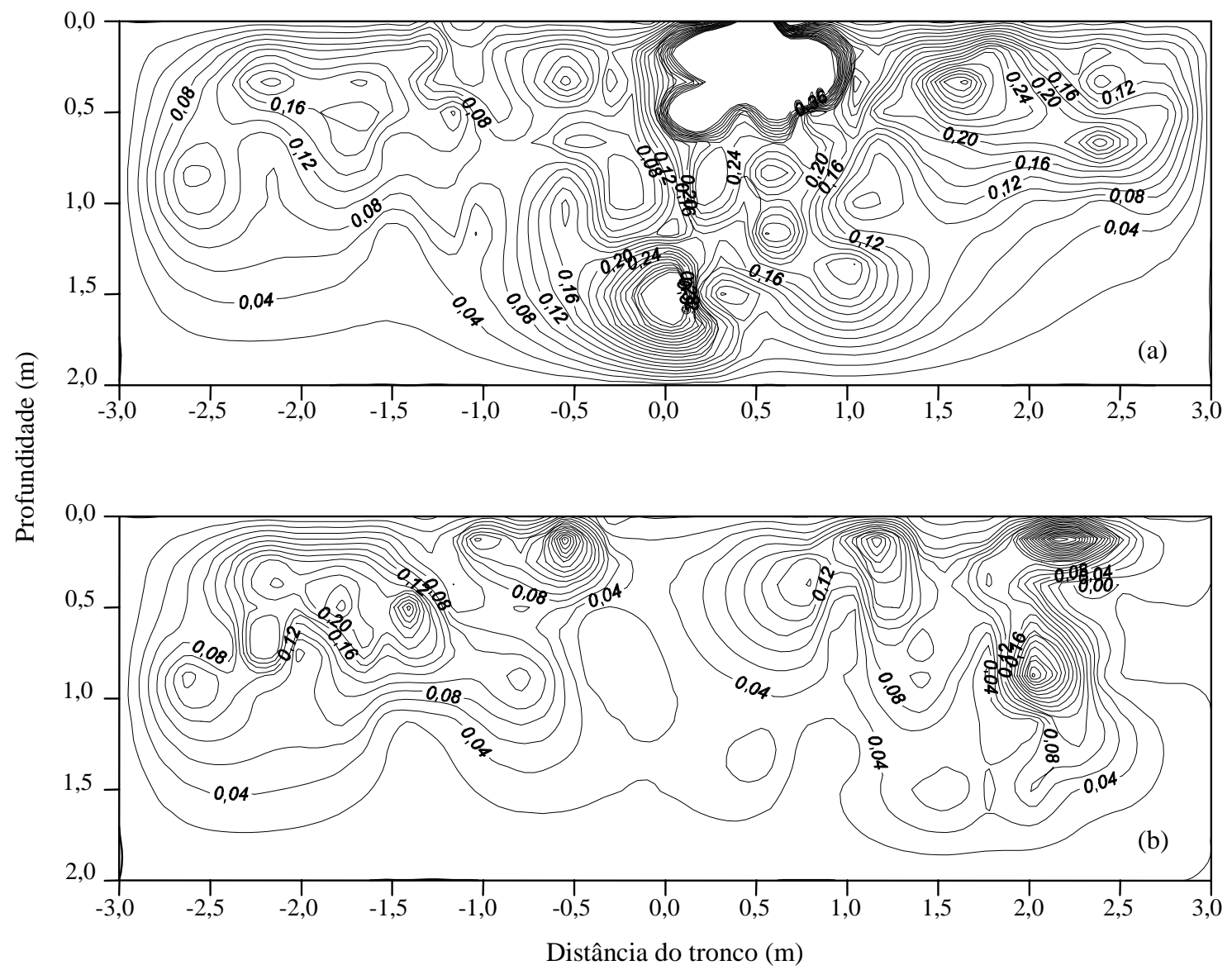

Figura 1. Distribuição de densidade de comprimento de raízes $\left(\mathrm{cm} \mathrm{cm}^{-3}\right)$ em dois perfis (a) na direção ortogonal à fileira de plantas e (b) na direção longitudinal à fileira de plantas, no sistema de irrigação por microaspersão. 
aos sensores, podem ser instalados em qualquer distância horizontal do tronco inferior a $2,5 \mathrm{~m}$, e em profundidades entre 0 e $1,0 \mathrm{~m}$ na irrigação por microaspersão, sendo mais adequada a instalação a distâncias horizontais do tronco entre 0,5 e 2,0 m.

Em todos os perfis avaliados, tanto na direção da fileira de plantas, como na direção ortogonal à fileira de plantas, houve coincidência entre as regiões de maiores valores de densidade de comprimento das raízes e as regiões de maior porcentagem de raízes finas, consideradas as mais responsáveis pela atividade de absorção de água e nutrientes.

Mesmo assumindo uniformidade na área experimental, pode-se afirmar que as distribuições de DCR e de diâmetros de outras árvores não serão semelhantes às obtidas; entretanto, espera-se que os padrões de distribuição das raízes quanto aos limites das regiões contendo as diferentes classes de diâmetros e DCR sejam uniformes. A uniformidade desses padrões quanto aos limites da distribuição de raízes deve-se principalmente ao fato de que o teor de água é o fator principal que favorece o desenvolvimento e a atividade das raízes durante o período seco do ano, que se estende por pelo menos seis meses na região. A uniformidade de distribuição de água dos microaspersores em relação ao solo e às plantas resulta numa geometria de fluxo de água uniforme no solo. As distribuições de raízes nos perfis sob condição não-irrigada (Tabela 1) foram condizentes com as distribuições obtidas por Zhang et al.
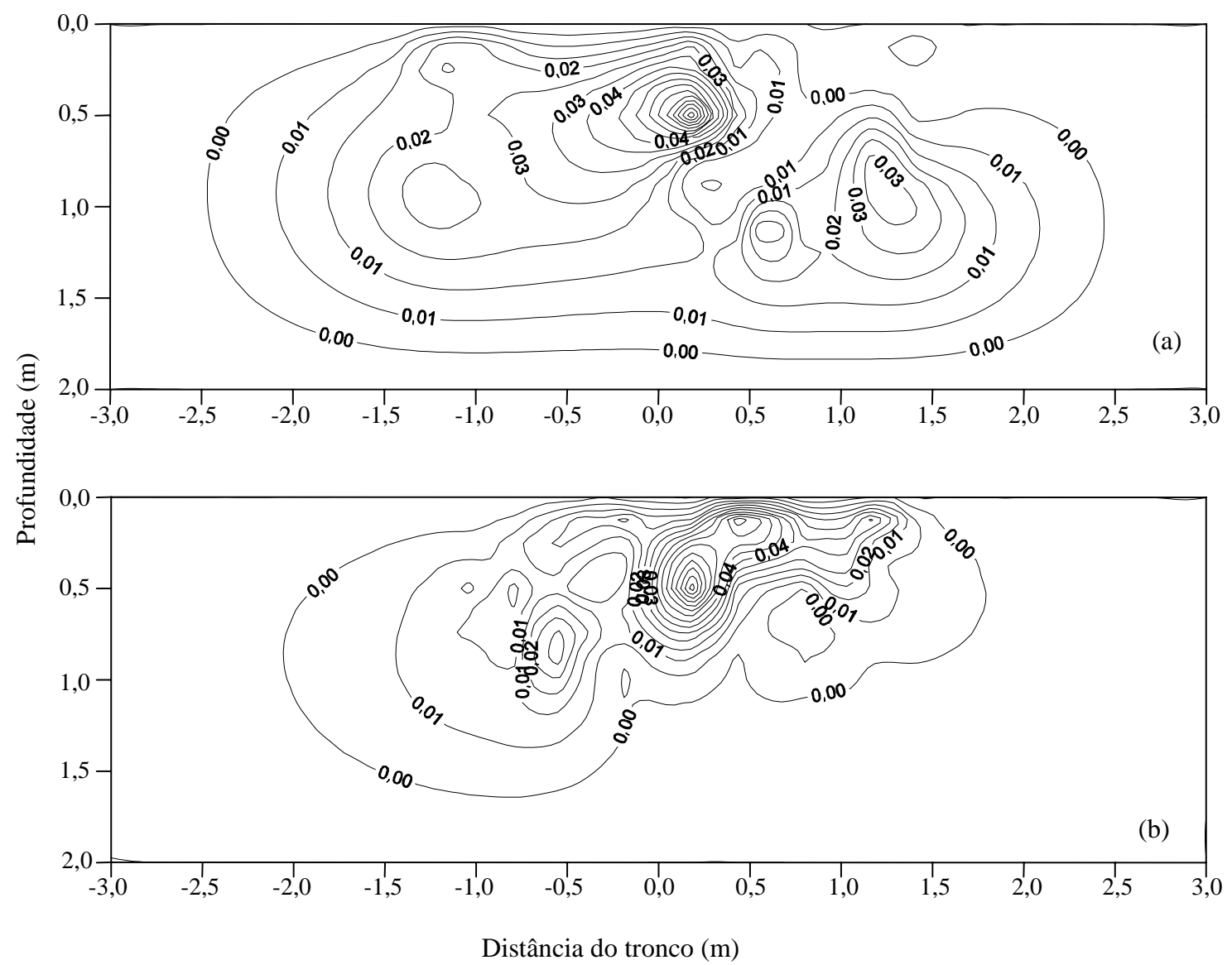

Figura 2. Distribuição de densidade de comprimento de raízes $\left(\mathrm{cm} \mathrm{cm}^{-3}\right) \mathrm{em}$ dois perfis (a) na direção ortogonal à fileira de plantas e (b) na direção longitudinal à fileira de plantas sob condições não-irrigadas. 
Ortogonal à fileira de plantas
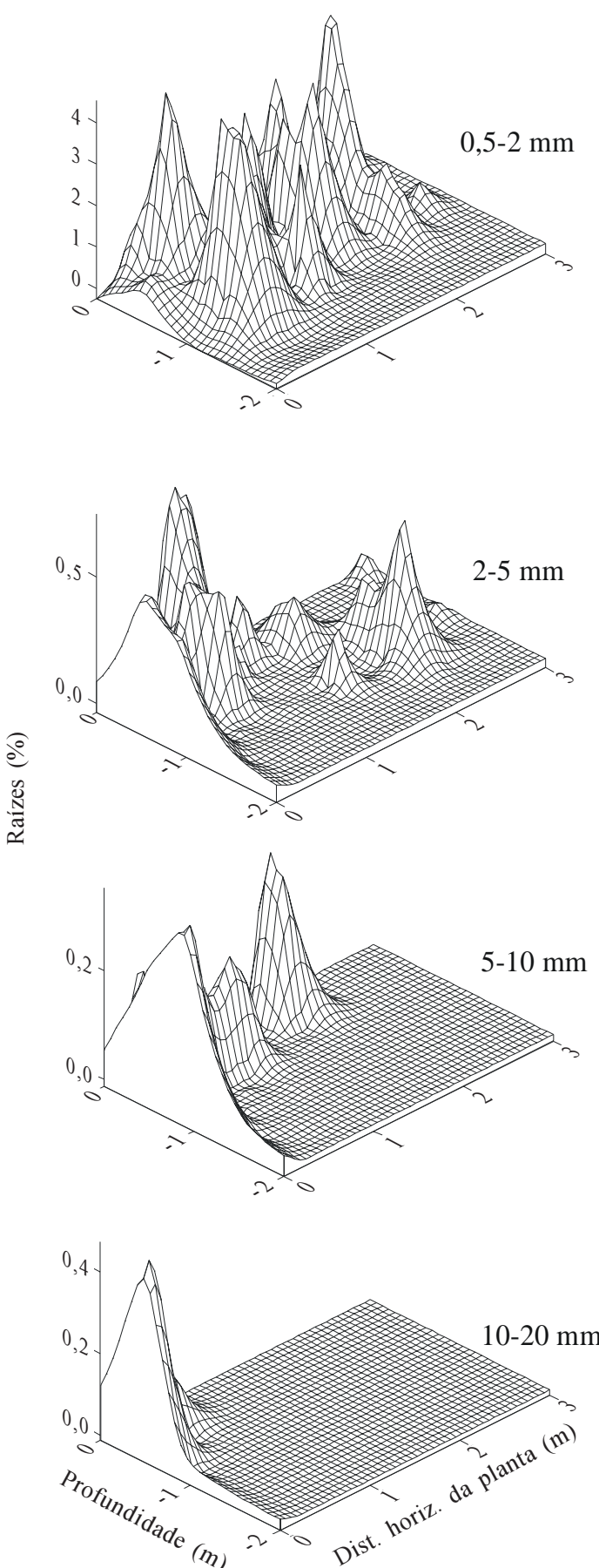

Figura 3. Porcentagens de comprimento de raízes de diferentes diâmetros relativos ao comprimento total de raízes em dois perfis (ortogonal e longitudinal à fileira de plantas), sob microaspersão, tendo a planta na posição 0 .
Longitudinal à fileira de plantas
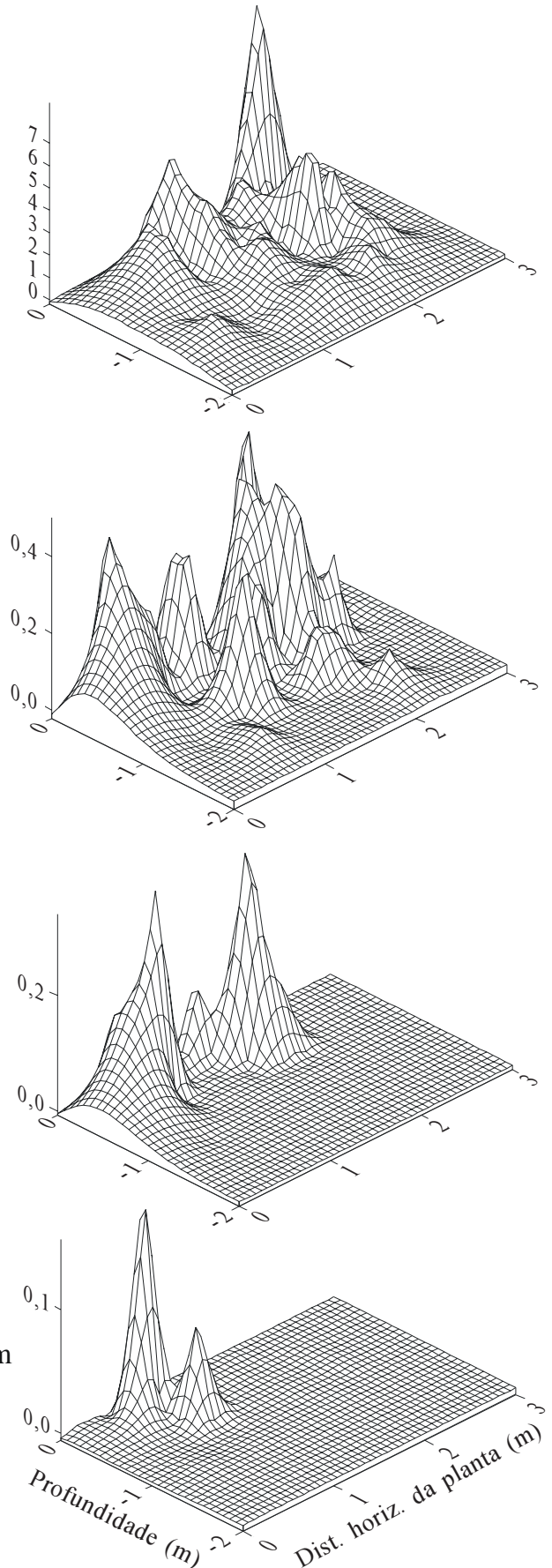

Pesq. agropec. bras., Brasília, v. 37, n. 5, p. 603-611, maio 2002 
Ortogonal à fileira de plantas
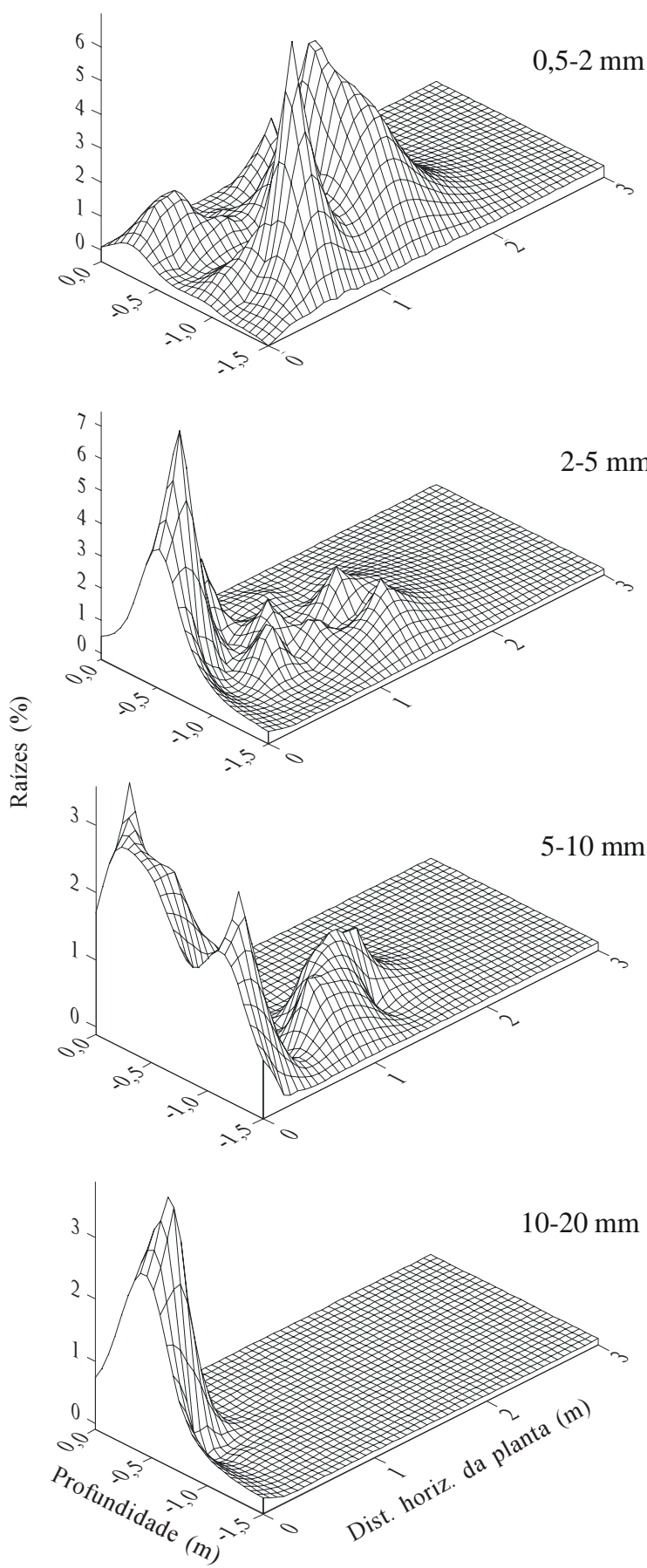

Longitudinal à fileira de plantas
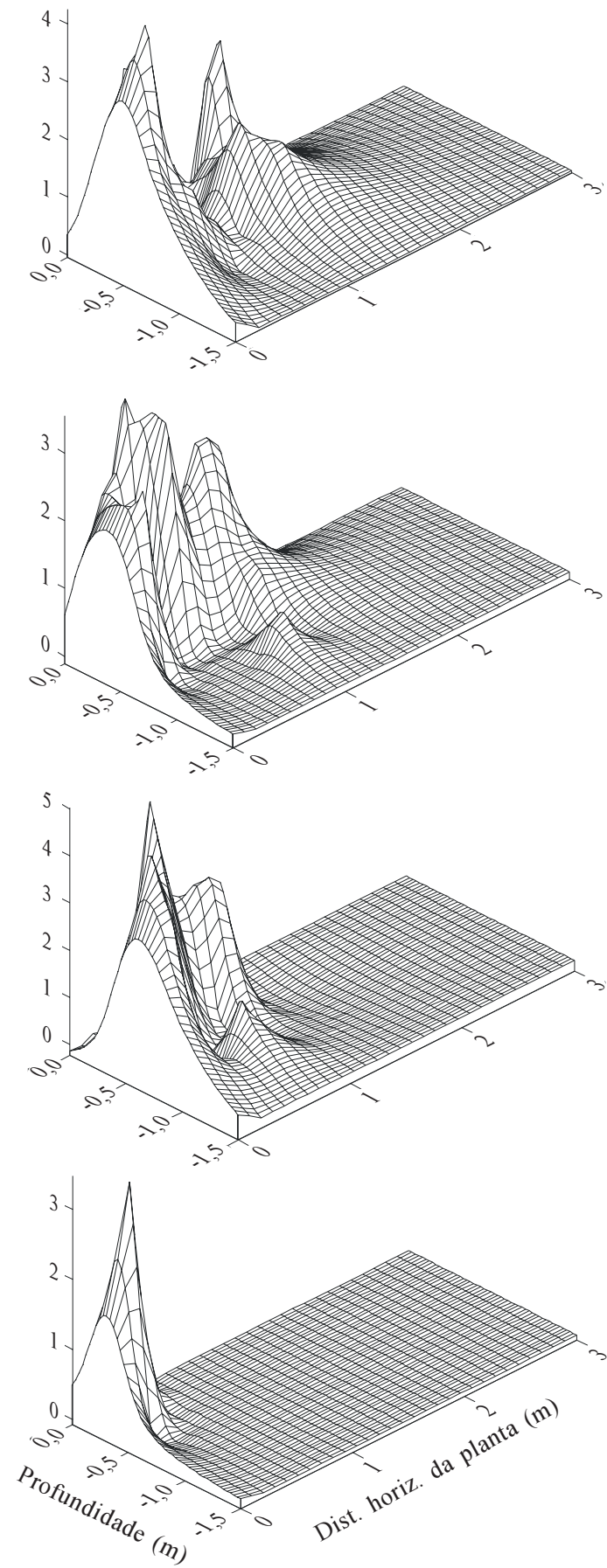

Figura 4. Porcentagens de comprimento de raízes de diferentes diâmetros relativos ao comprimento total de raízes em dois perfis (ortogonal e longitudinal à fileira de plantas) e sob condições não-irrigadas, tendo a planta na posição 0. 
(1996) e Carvalho et al.(1999), os quais obtiveram sistemas radiculares superficiais, com a maior parte das raízes entre 0 e $0,3 \mathrm{~m}$; entretanto, neste trabalho, nos perfis sob microaspersão, as profundidades entre 0 e 0,7 m contiveram entre $73 \%$ e $74 \%$ dos comprimentos totais de raízes, o que mostra uma diferença relevante entre os padrões de distribuição sob as condições irrigadas por microaspersão e não-irrigadas.

Ocorreram maiores porcentagens de raízes finas $(0,5$ a 2,0 mm) em relação às porcentagens de raízes pouco finas, médias e grossas, na planta sob microaspersão, do que na planta sob condição não-irrigada (Tabela 2 ). O maior volume molhado ocasionado pela microaspersão foi responsável pela maior expansão do sistema radicular e maior presença de raízes ativas. Considerando as raízes muito finas e finas como sendo as responsáveis pela absorção de água e nutrientes, pode-se inferir que a planta irrigada por microaspersão apresentou maior efici-

Tabela 1. Porcentagens dos comprimentos de raízes referentes a diferentes profundidades relativas ao comprimento total de raízes coletadas nos perfis na direção da fileira de plantas (L) e ortogonal à direção das fileiras $(\mathrm{O})$.

\begin{tabular}{ccccc}
\hline \multirow{2}{*}{$\begin{array}{c}\text { Posição } \\
\text { do perfil }\end{array}$} & \multicolumn{4}{c}{ Profundidades (m) } \\
\cline { 2 - 5 } & $0-0,3$ & $0,3-0,5$ & $0,5-0,7$ & $>0,7$ \\
\hline \multicolumn{5}{c}{ Sequeiro } \\
O & 30,4 & 28,9 & 17,9 & 22,7 \\
L & 44,4 & 25,3 & 17,0 & 13,3 \\
\cline { 2 - 5 } & \multicolumn{4}{c}{ Microaspersão } \\
O & 40,9 & 15,7 & 8,8 & 25,7 \\
L & 36,7 & 20,6 & 16,0 & 26,6 \\
\hline
\end{tabular}

Tabela 2. Porcentagens dos comprimentos de raízes referentes a classes de diferentes diâmetros em relação ao comprimento total coletado nos perfis, na direção da fileira de plantas (L) e ortogonal à direção das fileiras $(\mathrm{O})$.

\begin{tabular}{ccccccc}
\hline Posição & \multicolumn{6}{c}{ Classe de diâmetro (mm) } \\
\cline { 2 - 7 } do perfil & $<0,5$ & $0,5-2,0$ & $2,0-5,0$ & $5,0-10,0$ & $10,0-20,0$ & $>20$ \\
\hline \multicolumn{7}{c}{ Sequeiro } \\
O & 0,4 & 50,9 & 24,2 & 19,6 & 4,8 & 0,0 \\
$\mathrm{~L}$ & 0,0 & 31,4 & 31,7 & 30,9 & 6,0 & 0,0 \\
\cline { 2 - 7 } Microaspersão \\
O & 0,1 & 89,6 & 7,8 & 1,7 & 0,1 & 0,7 \\
$\mathrm{~L}$ & 0,0 & 90,4 & 7,3 & 2,0 & 0,1 & 0,2 \\
\hline
\end{tabular}

ência de absorção de água e nutrientes que a planta não-irrigada. Esse resultado reforça a afirmação de que a distribuição de água no solo constitui uma variável determinante na distribuição de raízes no solo sob microirrigação, o que concorda com Clausnitzer \& Hopmans (1994), Clothier \& Green (1994) e Coelho \& Or (1996).

\section{Conclusões}

1. As regiões de maiores valores de densidade de comprimento das raízes correspondem às regiões de maior incidência de raízes muito finas e finas, tanto sob condição irrigada como não-irrigada.

2. O sistema radicular da laranja apresenta maior expansão em profundidade e em distância radial do tronco sob irrigação por microaspersão do que sob condições não-irrigadas.

3. As posições mais adequadas para instalação de sensores de água do solo para a cultura da laranja sob microaspersão situam-se entre 0,5 e 2,0 m de distância radial a partir do tronco, em profundidades entre 0 e $1,0 \mathrm{~m}$.

4. A distribuição de água no solo, sob irrigação localizada, constitui uma variável determinante nos padrões de distribuição das raízes no solo.

\section{Referências}

BOHM, W. Methods of studying root systems. New York: Springer, 1979. $190 \mathrm{p}$.

BOletim AgrometeorolóGiCo. Parnaíba: Embrapa-CNPAI, v. 3, 1992. 44 p.

BOWEN, G. D. Roots as a component of tree productivity. In: CANNELL, M. G. R.; JACKSON, J. E. (Ed.). Attributes of trees as crop plants. Huntingdon: Institute of Terrestrial Ecology, 1985. p. 303-315.

CARVALHO, J. E. B.; SOUZA, L. S.; JORGE, L. A. C.; RAMOS, W.; COSTA NETO, A. O.; ARAÚJO, A. M. A.; LOPES, L.; JESUS, M. Manejo de coberturas do solo e sua interferência no desenvolvimento do sistema radicular da laranja pêra. Revista Brasileira de Fruticultura, Jaboticabal, v. 21, n. 2, p. 140-145, 1999.

CLAUSNITZER, V.; HOPMANS, J. W. Simultaneous modeling of transient three-dimensional root growth and soil water flow. Plant and Soil, Dordrecht, v. 164, p. 299314, 1994. 
CLOTHIER, B. E.; GREEN, S. R. Root zone processes and the efficient use of irrigation water. Agricultural Water Management, Amsterdam, v. 25, p. 1-12, 1994.

COELHO, E. F.; OLIVEIRA, F. C.; VASCONCELOS, L. F. L.; ARAUJO, E. C. E. Comparação de métodos de obtenção de imagens digitais de raízes. In: CONGRESSO BRASILEIRO DE ENGENHARIA AGRÍCOLA, 28. 1999, Pelotas. Anais... Pelotas: Sociedade Brasileira de Engenharia Agrícola/UFPel, 1999. 1 CD-ROM.

COELHO, E. F.; OR, D. A parametric model for twodimensional water uptake by corn roots under drip irrigation. Soil Science Society of America Journal, Madison, v. 60, p. 1039-1049, 1996.

GREGORY, P. J. Development and growth of root systems. In: GREGORY, P. J.; LAKE, J. V.; ROSE, D. A. Root development and function. New York: Cambridge University Press, 1987. p. 146-166.

KANBER, R.; KOKSAL, H.; ONDER. S.; EVLEN, M. Effects of different irrigation methods on yield, evapotranspiration and root development of young orange trees. Turkish Journal of Agriculture and Forestry, Ankara, v. 20, n. 2, p. 163-172, 1996.

KASPAR, T. C.; EWING, R. P. Rootedge: software for measuring root length from desktop scanner images. Agronomy Journal, Madison, v. 89, p. 932-940, 1997.

KLEPPER, B. Origin, branching and distribution of root systems. In: GREGORY, P. J.; LAKE, J. V.; ROSE, D. A. Root development and function. New York: Cambridge University Press, 1987. p. 103-123.

OLIVEIRA, F. C. H.; VIEIRA, D. B.; SOUZA, I. F.; OLIVEIRA, L. F. C.; SOUSA, I. S. Estudo do sistema radicular da tangerineira 'Cleopatra' com copa de laranjeira 'Pêra'. Laranja, Cordeirópolis, v. 19, n. 1, p. 117-131, 1998.

ZHANG, M.; ALVA, A. K.; LI, Y. C.; CALVERT, D. V. Root distribution of grapefruit trees under dry granular broadcast vs. fertirrigation method. Plant and Soil, Dordrecht, v. 183, n. 1, p. 79-84, 1996. 